\title{
Maternal predictors of infant beverage consumption: results from the Nurture cohort study
}

\author{
Alison Tovar ${ }^{1, *}$, Maya Vadiveloo ${ }^{1}$, Truls $\varnothing_{\text {stbye }}{ }^{2}$ and Sara E Benjamin-Neelon ${ }^{3}$ \\ 'Department of Nutrition and Food Sciences, University of Rhode Island, Kingston, RI 02881, USA: ${ }^{2}$ School of \\ Medicine, Community and Family Medicine, Duke University Medical Center, Durham, NC, USA: ${ }^{3}$ Johns Hopkins \\ Bloomberg School of Public Health, Baltimore, MD, USA
}

Submitted 15 August 2018: Final revision received 22 January 2019: Accepted 19 February 2019: First published online 20 May 2019

\begin{abstract}
Objective: The goal of the present study was to estimate prevalence and maternal risk factors for infant beverage consumption.

Design: Observational birth cohort.

Setting: Central North Carolina, USA.

Participants: Mothers 20-36 weeks pregnant were surveyed every 3 months through their infant's first year ( $n$ 666) on their sociodemographics and infant's consumption frequency of $100 \%$ fruit and vegetable juices and sugar-sweetened-beverages (SSB). Repeated-measure models, using a compound symmetry covariance structure, were used to assess the association of sociodemographic and maternal predictors with introducing juice and SSB separately and explored interaction terms with time to determine how the effects of the predictors change over time.

Results: On average, mothers were 28 years old, $72 \%$ were non-Hispanic Black and $59 \%$ were low-income. We found time by race, income, education, maternal age and breast-feeding duration interactions for both juice and SSB consumption. At approximately 6-7 months of age through 12 months of age, being Black, having a lower income ( $\leq \$$ US $20000 v$. > \$US 20000 per year) and education (less than high-school degree $v$. high-school degree or higher), being younger ( $<26$ years $v$. $\geq 26$ years) and breast-feeding for fewer than 26 weeks were each associated with introduction of both juice and SSB consumption.

Conclusions: Future efforts are needed to raise awareness on the importance of national recommendations of limiting juice and SSB for infants, together with decreasing disparities in unhealthy beverage intake early in life.
\end{abstract}

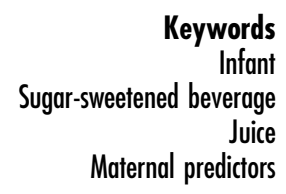

Feeding habits established early in life can influence diet and health later in life. In particular, exposure to breast milk and other first beverages and foods can play an important role in shaping food preferences and later eating habits ${ }^{(1)}$. During the first year of life, infants should consume breast milk or formula as their primary beverage ${ }^{(2,3)}$. Unfortunately, before their first birthday most infants are being introduced to sugary foods including desserts, sweets and sugar-sweetened beverages $(\mathrm{SSB})^{(4)}$. Furthermore, they are also being introduced to different types of juice, which is not recommended during the first year of life $\mathrm{e}^{(5)}$. These beverages can displace healthier options and contribute a significant amount of energy to children's diets ${ }^{(6)}$. Consumption of sugary beverages during infancy has been associated with obesity ${ }^{(7)}$ and an increased likelihood of continued consumption of these beverages later in life ${ }^{(8)}$. Furthermore, consumption of sugary beverages has also been associated with asthma ${ }^{(9)}$, dental caries $^{(10)}$ and poor academic grades in children ${ }^{(11)}$. Although the risks associated with consumption of sugary beverages during the first year of life have been documented, it is unclear what some of the maternal predictors of consumption during infancy may be. A better understanding of such predictors can inform future interventions and other efforts to reduce consumption.

Sugary beverage consumption is more common among racial and ethnic minority groups and those of low socioeconomic status ${ }^{(12-17)}$. Recent National Health and Nutrition Examination Survey (NHANES) data found that although there was a decline in the prevalence of $100 \%$ fruit juice consumption among 6- to 11 -month-olds from $60.2 \%$ in $2005-2008$ to $47.7 \%$ in 2009-2012, the prevalence remains relatively high. In addition, this decline differs by racial/ethnic minority group, with significant declines among non-Hispanic Whites and 
non-Hispanic Blacks but not Mexican Americans. Similarly, a significant decline from 74.7 to $60.3 \%$ was observed among older infants participating in the Special Supplemental Nutrition Program for Women, Infants, and Children (WIC), who had a higher prevalence of fruit juice consumption than infants in this age group overall. Also concerning, there was an increase in sugary beverage consumption from $2 \cdot 0$ to $9.9 \%$ among nonHispanic Blacks as compared with a decrease among non-Hispanic Whites from $11 \cdot 3$ to $10 \cdot 0 \%{ }^{(18)}$. Another study conducted with NHANES data found that non-Hispanic Black children consumed the most $100 \%$ juice and SSB during the first 3 years of life, followed by Hispanic children, as compared with White and Asian children ${ }^{(19)}$. Furthermore, infant beverage consumption may differ by other maternal characteristics, such as maternal education, age or maternal weight status ${ }^{(20)}$. Most studies to date, however, have focused on older children and adults with no studies exploring maternal predictors of infant beverage consumption, which may help explain very early health disparities. Moreover, no studies have explored SSB in addition to juice, both of which are not recommended during the first year of life. Therefore, the goal of the present study was to estimate the prevalence and maternal risk factors for infant beverage consumption, including both sugary beverages and juice.

\section{Methods}

Data for the current analysis came from the Nurture study, a cohort of predominantly Black mothers and their infants residing in the Southeast USA. The Nurture study is an observational birth cohort designed to assess longitudinal associations of early childcare and multiple caregivers with infant adiposity and weight trajectories throughout the first year of life. Women were recruited and enrolled in mid-to-late pregnancy from a private prenatal clinic and the local county Health Department prenatal clinic in Durham, North Carolina. Women provided written informed consent to participate at enrolment and again at the birth of their infants when they provided additional consent for both themselves and their infants. Details of the cohort have been published elsewhere ${ }^{(21)}$. The study was approved by the Institutional Review Board at the Duke University Medical Center (Human Subjects Committee; Pro 00036242).

\section{Measures}

Data collection took place from 2013 to 2016. Home visits were conducted when infants were 3, 6, 9 and 12 months of age. Women received automated interactive voice response telephone calls in months $1,2,4,5,7,8,10$ and 11 to assess a limited set of behaviours, including caregiving arrangements, infant feeding practices, infant motor milestone achievement and infant sleep.

\section{Beverage consumption}

Mothers reported all beverages provided to infants via questionnaire at each home visit using questions from the Infant Feeding Practices Study II (IFPS II) and the Feeding Infants and Toddlers Study (FITS) ${ }^{(22,23)}$. The beverage consumption question asked 'Did your baby try or drink [beverage] any time from birth to 1 month of age [asked up to 12 months of age]?', with responses of 'never', 'just to try', 'sometimes but less than once per day', ' 1 time per day' with options up to ' 5 or more times per day'. During the initial data collection period, the fruit and vegetable juice question and the SSB question were asked as two questions. Early in the data collection period, in order to refine the data collection process, these questions were separated out into fruit juice and vegetable juice (two questions) and into juice drinks, sweet teas and soft drinks (three questions). We utilized both types of variable to create our outcome variables. For juice, we used the combined question for those who reported it in this way and then summed the frequency of fruit and vegetable juice consumption for the remainder. The same approach was taken for the SSB variable; when the SSB combined variable was available we used that and summed the three separate variables to create the outcome SSB variable.

\section{Maternal predictors}

Sociodemographic information was recorded from mothers via interviews and questionnaires at recruitment, at birth, and during each home visit and each call. Based on the prior literature, maternal variables of interest for the current analysis included race, age, education, working hours, number of children under the age of 18 years in the household, receiving benefits from WIC and pre-pregnancy $\mathrm{BMI}^{(24)}$. At enrolment and at each home visit, we asked mothers to report household income and provided the following categories ( $\leq$ \$US 20000 , \$US $20000-40000$, \$US $40000-70000$ and $>$ \$US 70000 per year).

Maternal predictors were dichotomized to reflect meaningful groups as follows: maternal race (Black $v$. nonBlack), household income ( $\leq$ \$US $20000 v$. > \$US 20000 per year to reflect the 2018 federal poverty guidelines for a household of three members), maternal education (less than high-school degree $v$. high-school degree or higher), maternal hours of work reported during pregnancy ( $<35 \mathrm{~h} /$ week $v . \geq 35 \mathrm{~h} /$ week), maternal age ( $<26$ years $v$. $\geq 26$ years) and maternal pre-pregnancy BMI (normal weight $v$. overweight/obese). Mothers reported if they breast-fed via questionnaire at each home visit. Any breast-feeding was dichotomized into $<26$ weeks of breast-feeding (equivalent to 6 months) $v$. $\geq 26$ weeks of breast-feeding to reflect current breast-feeding guidelines ${ }^{(25)}$. Mothers also reported exclusive breast-feeding but given the low numbers breast-feeding exclusively (66.0\% no exclusive breast-feeding, $20.4 \%$ exclusive for 
1-6 months and $13.4 \%$ exclusive for $6-12$ months), we utilized any breast-feeding as one of the predictors.

\section{Statistical analysis}

Frequencies across maternal predictors were explored and $\chi^{2}$ analysis was used for unadjusted associations. Repeatedmeasure models, using a compound symmetry covariance structure, were used to assess the association of sociodemographic and maternal predictors with introducing juice and SSB separately, and explored interaction terms with time to determine how the effects of the predictors change over time. Model fit was assessed using Akaike information criterion and Bayesian information criterion fit statistics. Least-square means for each of the predictors at each of the time points were assessed. All analyses were conducted using the statistical software package SAS version 9.4 at a significance level of $P<0.05$.

\section{Results}

Overall, mothers in the sample were $71.8 \%$ Black, with $60.8 \%$ having a household income of $\leq \$$ US 20000 /year and $47.8 \%$ having less than a high-school degree. Close to half reported working fewer than $35 \mathrm{~h}$ /week $(47.0 \%)$ and were less than 26 years of age (47.6\%). Three-quarters breast-fed for fewer than 26 weeks $(77.5 \%)$ and more than half were overweight/obese ( $63.2 \%$; Table 1).

Overall, $17.1 \%$ of infants aged $1-4$ months, $54.9 \%$ of infants aged 5-8 months and $75.0 \%$ of infants aged 9-12 months were introduced to juice, respectively, for each time point. Similarly, $3.9 \%$ of infants aged $1-4$ months, $16.4 \%$ of infants aged $5-8$ months and $33.1 \%$ of infants aged 9-12 months were introduced to SSB, respectively, for each time point.

\section{Introduction of juice consumption}

In mixed models, there was a race by time interaction and between months 7 and $12(v$. month 3$)$, being Black $v$. other races was associated with an increased introduction of juice consumption (month 7, $\beta=0.51, P=0.005$; month 8, $\beta=0.80, P<0.0001$; month 9, $\beta=0.90, P<0.0001$; month 10, $\beta=0.83, P<0.0001$; month 11, $\beta=0.93, P<0.0001$; month 12, $\beta=1 \cdot 11, P<0.0001$; Fig. 1(a)).

Similarly, there was an income by time interaction and at months 6, 9 and $12(v$. month 3$)$, being lower income ( $\leq \$$ US 20 000/year) $v$. higher income (>\$US 20 000/year) was associated with increased introduction of juice consumption (month 6, $\beta=0.46, P=0.03$; month 9, $\beta=0.65$, $P=0.002$; month $12, \beta=0.76, P=0.0004$ ).

There was also an education by time interaction and at months $7-12$ ( $v$. month 3$)$, having less than a high-school degree $v$. having a high-school degree or higher was associated with increased introduction of juice consumption (month 7, $\beta=0.58, P=0.0008$; month $8, \beta=0.57$,
Table 1 Sociodemographic characteristics of mothers participating in the Nurture cohort study ( $n$ 666), central North Carolina, USA, 2013-2016

\begin{tabular}{|c|c|c|}
\hline & $n$ & $\%$ \\
\hline \multicolumn{3}{|l|}{ Race } \\
\hline Black & 476 & 71.8 \\
\hline Non-Black & 187 & $28 \cdot 2$ \\
\hline \multicolumn{3}{|l|}{ Household income } \\
\hline$\leq \$$ US $20000 /$ year & 369 & $60 \cdot 8$ \\
\hline >\$US 20 000/year & 238 & $39 \cdot 2$ \\
\hline \multicolumn{3}{|l|}{ Education } \\
\hline Less than high-school degree & 318 & $47 \cdot 8$ \\
\hline High-school degree or higher & 347 & $52 \cdot 2$ \\
\hline \multicolumn{3}{|l|}{ Working hours } \\
\hline$<35 \mathrm{~h} /$ week & 155 & $47 \cdot 0$ \\
\hline$\geq 35 \mathrm{~h} /$ week & 175 & $53 \cdot 0$ \\
\hline \multicolumn{3}{|l|}{ Age } \\
\hline$<26$ years & 317 & 47.6 \\
\hline$\geq 26$ years & 349 & $52 \cdot 4$ \\
\hline \multicolumn{3}{|l|}{ Breast-feeding duration } \\
\hline$<26$ weeks & 509 & $77 \cdot 5$ \\
\hline$\geq 26$ weeks & 148 & $22 \cdot 5$ \\
\hline \multicolumn{3}{|l|}{ Pre-pregnancy BMI } \\
\hline Normal & 229 & $36 \cdot 8$ \\
\hline Overweight/obese & 393 & $63 \cdot 2$ \\
\hline
\end{tabular}

$P=0.0009 ;$ month 9, $\beta=0.49, \quad P<0.004 ;$ month 10, $\beta=0.56, \quad P=0.0009 ;$ month $11, \quad \beta=0.65, \quad P<0.0001$; month $12, \beta=0.78, P<0.0001$; Fig. $1(\mathrm{~b}))$.

There was a significant maternal age by time interaction and starting at month 7 , being younger $(<26$ years) $v$. older ( $\geq 26$ years) was associated increased introduction of juice consumption (month 7, $\beta=0.48, P=0.006$; month 8, $\beta=0.49, P=0.006$; month 9, $\beta=0.40, P=0.02$; month $10, \beta=0.53, P=0.002$; month 11, $\beta=0.64, P=0.0002$; month 12, $\beta=0.79, P<0.0001$; Fig. 1(c)).

There was a significant breast-feeding by time interaction and starting at month 7 , breast-feeding for $<26$ weeks $v$. breast-feeding for $\geq 26$ weeks was associated with increased introduction of juice consumption (month $7, \beta=0.70$, $P=0.0002$; month 8, $\beta=0.74, \quad P<0.0001 ;$ month 9, $\beta=0.82, P<0.0001$; month 10, $\beta=0.85, P<0.0001$; month 11, $\beta=0.92, P<0.0001$; month 12, $\beta=1.10, \quad P<0.0001$; Fig. 1(d)).

Number of children, maternal hours of work, receiving WIC benefits and maternal BMI were not significant predictors on their own nor did they have significant interactions by time.

\section{Introduction of sugar-sweetened beverage consumption}

Similar to juice consumption, in mixed models, there were time interactions with race, income, education, maternal age and breast-feeding duration.

For race, between months 9 and 12 ( $v$. month 3), being Black $v$. other races was associated with an increased introduction of SSB consumption (month $9, \beta=0 \cdot 35, P=0.03$; month 10, $\beta=0.54, \quad P=0.0004 ;$ month $11, \quad \beta=0.62$, $P<0.0001$; month 12, $\beta=0.77, P<0.0001$; Fig. $2($ a)). 


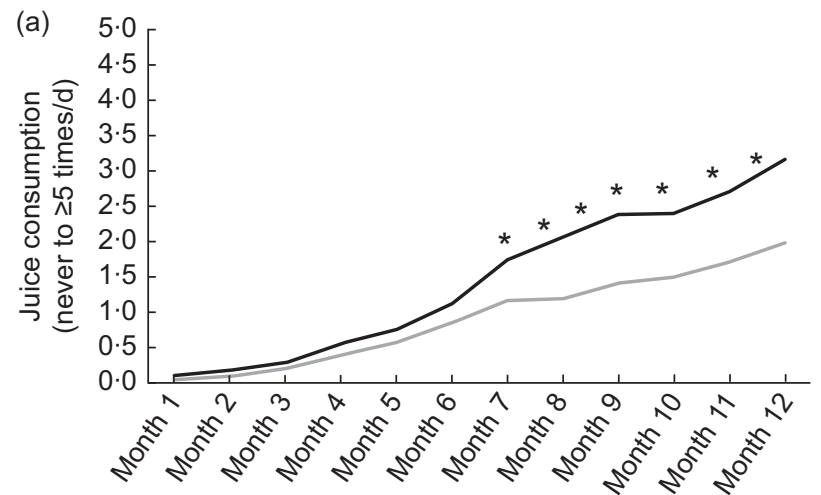

(c)

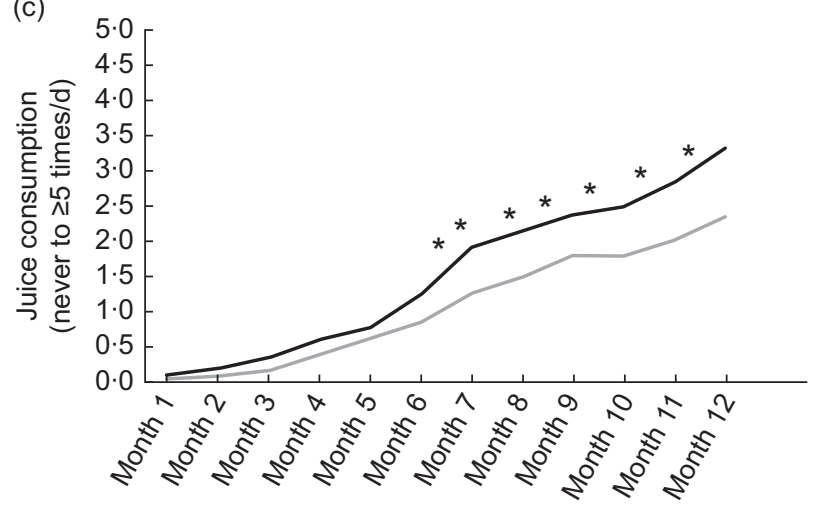

(b)

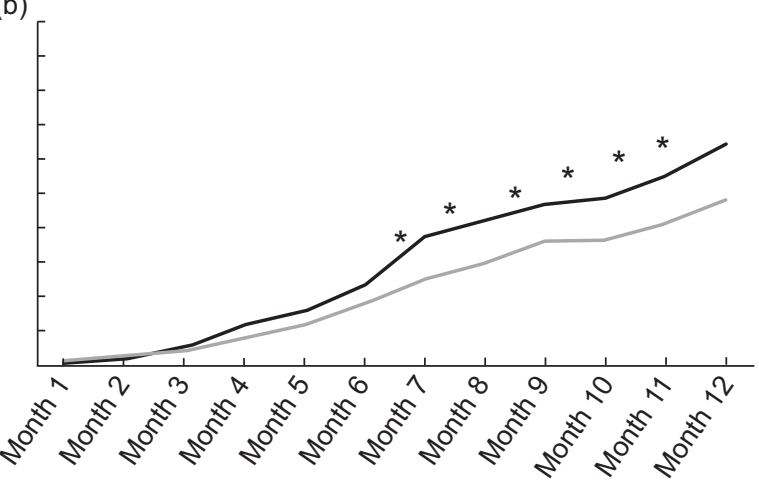

(d)

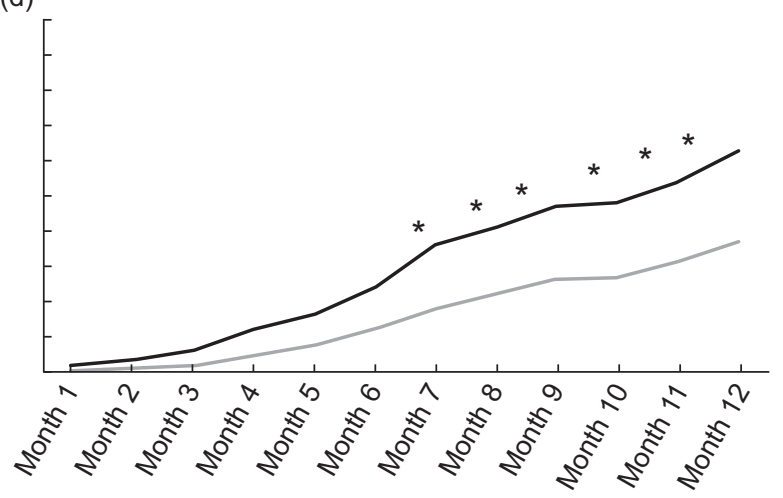

Fig. 1 Infant least-squared adjusted monthly mean juice consumption during the first year of life by maternal predictors: (a) race (- Black; - - other races); (b) education (- less than high-school degree; - , high-school degree or higher); (c) age (—, <26 years; — - $\geq 26$ years); and (d) breast-feeding duration (- $<26$ weeks; —,$\geq 26$ weeks); Nurture cohort study ( $n$ 666), central North Carolina, USA, 2013-2016. * Statistically significant predictor $\times$ time interaction $(P<0 \cdot 05)$

Similarly, there was an income by time interaction, but only at month $12(v$. month 3$)$ was being lower income ( $\leq \$$ US 20000 per year) $v$. higher income ( $>$ US $20000 /$ year) associated with increased introduction of SSB consumption (month $12, \beta=0.85, P<0.0001$ ).

Similar to juice consumption, there was an education by time interaction; at months 7-12 ( $v$. month 3$)$, having less than a high-school degree $v$. having a high-school degree or higher was associated with increased introduction of SSB consumption (month $7, \beta=0.35, P=0.02$; month 8 , $\beta=0.38, P=0.009$; month 9, $\beta=0.52, P=0.0004$; month $10, \beta=0.52, P=0.0009$; month $11, \beta=0.64, P<0.0001$; month 12, $\beta=0.75, P<0.0001$; Fig. 2(b)).

There was a significant maternal age by time interaction and starting at month 9 , being younger ( $<26$ years) $v$. older age ( $\geq 26$ years) was associated with increased introduction of SSB consumption (month 9, $\beta=0.3, P=0.04$; month 10, $\beta=0.57, P<0.0001$; month $11, \beta=0.77, P<0.0001$; month $12, \beta=0.84, P<0.0001$; Fig. $2(\mathrm{c}))$.

There was a significant breast-feeding by time interaction and starting at month 7 , breast-feeding for $<26$ weeks $v$. breast-feeding for $\geq 26$ weeks was associated with increased introduction of SSB consumption (month 7, $\beta=0.41, P=0.009$; month $8, \beta=0.45, P=0.005$; month 9, $\beta=0.68, P<0.0001$; month $10, \beta=0.89, P<0.0001$; month 11, $\beta=0.94, \quad P<0.0001$; month $12, \quad \beta=1.10$, $P<0.0001$; Fig. 2(d)).

Number of children, maternal hours of work, receiving WIC benefits and maternal BMI were not significant predictors on their own nor did they have significant interactions by time.

\section{Discussion}

In this sample of low-income mothers and their infants, close to three-quarters of infants were introduced to juice during the first 12 months and one-third were introduced to SSB during that time. We found time by race, income, education, maternal age and breast-feeding duration interactions. At approximately 6-7 months of age, the mother being Black, having a lower income and education, being younger and breast-feeding for fewer than 26 weeks were associated with introduction of both juice and SSB consumption. Continued efforts to decrease the disparities in juice and beverage consumption between these groups, starting at the time that introduction of foods is beginning, is critical.

The findings that close to three-quarters of infants are introduced to juice and one-quarter to SSB by their first 
Maternal predictors of infant beverage intake infant beverage intake
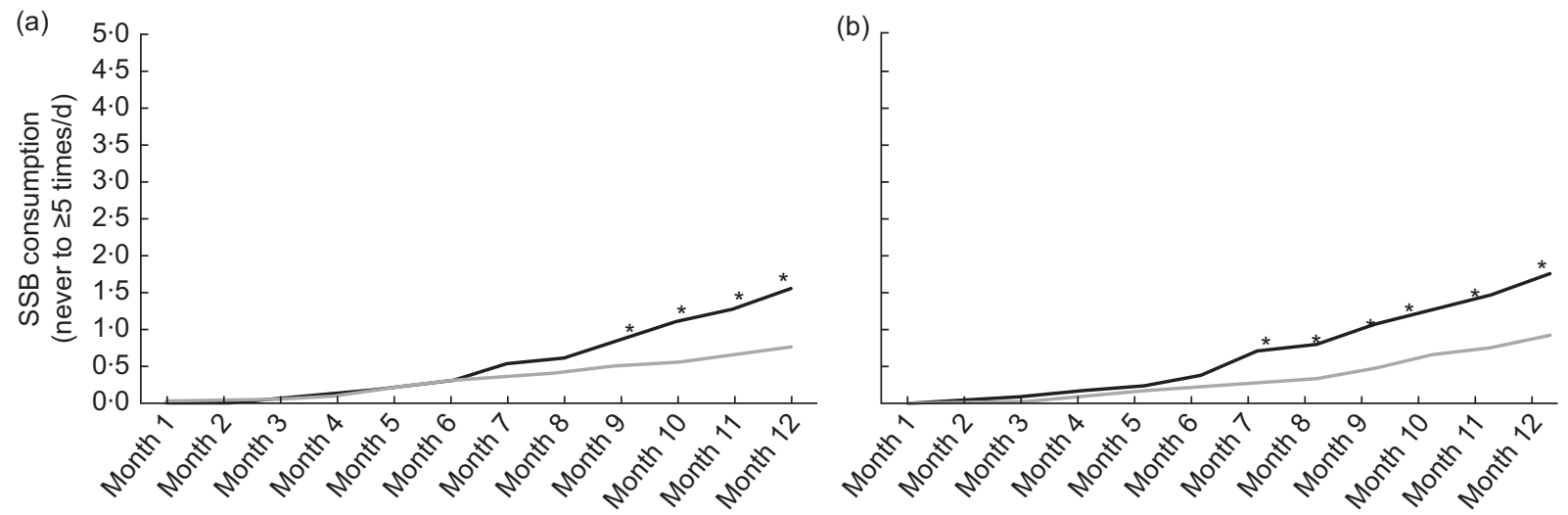

(c)

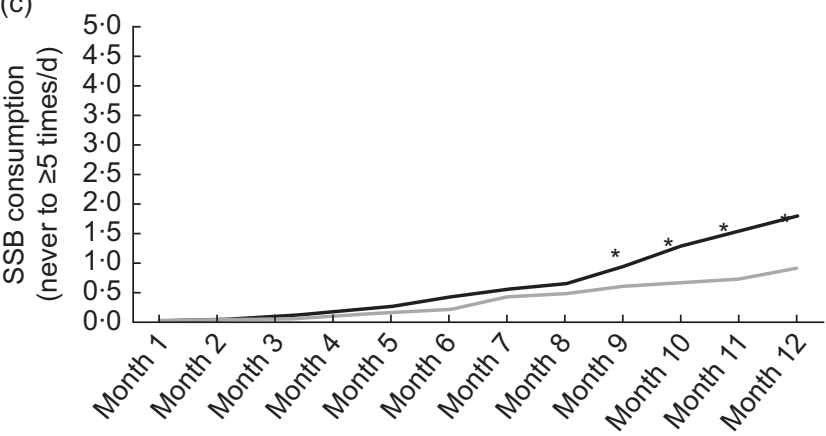

(d)

Fig. 2 Infant least-squared adjusted monthly sugar-sweetened beverage (SSB) consumption during the first year of life by maternal predictors: (a) race (_, Black; — other races); (b) education (- less than high-school degree; - , high-school degree or higher); (c) age (—, <26 years; — , $\geq 26$ years); and (d) breast-feeding duration (-, <26 weeks; —, $\geq 26$ weeks); Nurture cohort study ( $n$ 666), central North Carolina, USA, 2013-2016. ${ }^{\star}$ Statistically significant predictor $\times$ time interaction $(P<0 \cdot 05)$

birthday add to the growing literature on beverage consumption during the first year of life. The IFPS II found that at 12 months, $77 \%$ of infants were consuming fruit juice ${ }^{(26)}$, which is consistent with our data and with the FITS data ${ }^{(4)}$. Our data are also similar to NHANES data, whereby $6 \%$ of 0- to 6-month-olds and $38 \%$ of 6- to 12-month-olds consumed juice. For SSB, NHANES data revealed that $1 \%$ of 0 - to 6-month-olds and $6 \%$ of 6-to 12-month-olds were consuming $\mathrm{SSB}^{(27)}$. For our population this was closer to $30 \%$ by month 12 . SSB constitute a major source of added sugar and energy intake in the US diet ${ }^{(28)}$ that could be replacing higher-quality nutritious beverages during critical periods of growth and development. Early juice and SSB consumption have been associated with increased risk for later and continued SSB consumption ${ }^{(8)}$, subsequent overweight/obesity and dental caries. Therefore, understanding factors that can help tailor interventions is important ${ }^{(29)}$.

The interaction effects between time and several of the maternal predictors on juice and SSB outcomes is not surprising and is consistent with previous studies ${ }^{(30)}$. Several of the differences observed are consistent with what is observed for the overall diet quality of the US population in general. It is possible that these differences are observed at approximately 6-7 months of age (and not before) because this is the time period where infants are developmentally ready to begin consuming other foods besides breast milk and formula and that the quality of beverages being introduced for Black, low-income/education populations is lower than that for other races, higher incomes and education. Other studies have found that with increasing age, and with the introduction of other foods, the disparities in SSB consumption with race are particularly evident ${ }^{(19)}$. Our results highlight that the differences observed in diet across different sub-populations occur early in life and that future studies should try to further understand what is driving these disparities.

Income disparities are apparent in the diet quality of infants and children, whereby low-income children have poorer diet quality. Similarly, there was a time by education interaction whereby, at approximately 7 months, mothers with lower education had higher risk of juice and SSB introduction. This is similar to what others have found. Although our study looked at having a high-school education or more, Hendriks et al. found that having a college education was the maternal characteristic associated with the largest number of positive child feeding behaviours ${ }^{(20)}$. Collegeeducated mothers were significantly more likely to comply with the American Academy of Pediatrics' juice and complementary feeding recommendations. Similarly, in the IFPS II, the prevalence of unhealthful feeding practices was inversely associated with maternal education ${ }^{(31)}$. 
Other studies have also found evidence of these sociodemographic differences in older children ${ }^{(32)}$ and in overall dietary patterns ${ }^{(33-35)}$. It is possible that mothers with lower incomes may be taking advice from family members rather than following health-care provider recommendations during this early time period ${ }^{(36)}$. This may be especially true around the time when infants are being introduced to solid foods. Furthermore, low-income groups may also just have less access to health resources and care. We also found a time by age interaction, whereby at approximately 7 months, younger mothers were more likely to introduce juice and SSB. This is consistent with another study with slightly older children (1-8 years) which found that SSB consumption was significantly higher in children from young mothers ${ }^{(37)}$. Other studies have also found higher maternal age to be associated with positive feeding practices $^{(20)}$. Future studies should explore reasons why these mothers may be introducing beverages very early in life and investigate how this can be prevented.

In looking at possible maternal predictors for introducing juice and SSB, overall breast-feeding for less than the recommended 6 months was associated with higher risk of introduction of juice and SSB starting at 6 months of age. These findings are similar to a national Norwegian study whereby among 1932 infants, those who were breast-fed until 12 months had lower intake of sweetened drinks and added sugars than non-breast-fed infants ${ }^{(38)}$. Similarly, another longitudinal cohort study found an inverse association between breast-feeding and consumption of $\mathrm{SSB}^{(39)}$. It is possible that mothers who choose to and are able to breastfeed for more than 26 weeks also choose other healthy practices for their children. It is also possible that infants who are displacing breast milk and/or formula for more sugary tastes during this critical time period are being set up for unhealthier diet patterns later in life, like reluctance to accept new foods such as vegetables given their bitter taste ${ }^{(40)}$. Future interventions and programmes that target mothers who do not breast-feed for 26 weeks should include information on the provision of other beverages.

Our study has some limitations. First, beverage introduction was self-reported, which is subject to under- or overreporting; however, the questions were adapted from prior cohort studies and are considered a reasonably valid and reliable tool for this population ${ }^{(22)}$. Second, vegetable and fruit juice were combined into one single variable on the questionnaire. Fruit juice tends to have a higher sugar content than vegetable juice and may have different effects on future taste preferences in infants and children. In this cohort however, vegetable juice consumption was low, with approximately $9 \%$ reporting any consumption by 6 months and $12 \%$ by 12 months. Third, women participating in the Nurture study were not entirely representative of the local population. At recruitment, women were recruited from one of two obstetric clinics. One clinic served a high percentage of low-income women (the local Health Department) and the other served a large proportion of higher-income, non-Hispanic White women with higher-risk pregnancies. However, the sample of women who enrolled had a higher percentage of Black women than the general population.

\section{Conclusion}

Examining beverage intake during the first year of life provides unique insight into a critical window when an infant's dietary patterns are being established. We found that this population of predominantly Black mothers introduced beverages to their infants very early in life and that racial, income and education differences were evident at approximately 6-7 months of age. Future efforts are needed to raise awareness on the importance of national recommendations of limiting juice and SSB for all infants. In addition, there is a particular need to decrease unhealthy beverage disparities early in life.

\section{Acknowledgements}

Financial support: This work was supported by the National Institutes of Health, Bethesda, MD, USA (grant number R01DK094841). The National Institutes of Health had no role in the design, analysis or writing of this article. Conflict of interest: None of the authors has any conflict of interest to disclose. Authorship: All authors contributed to the various stages of this study. A.T. contributed to the study design, performed all statistical analyses and drafted the manuscript. M.V. contributed to the study design and reviewed the statistical analysis and the manuscript. T. $\varnothing$. participated in discussion of the design of the study and revised the manuscript. S.E.B.-N. conceived of the initial idea of the study, contributed to the design of the study, revised the manuscript and contributed especially to the intellectual content. All the authors read and commented on the drafts and approved of the final version for submission. Ethics of buman subject participation: This study was conducted according to the guidelines laid down in the Declaration of Helsinki and all procedures involving research study participants were approved by the Duke University Medical Center Institutional Review Board (Human Subjects Committee; Pro 00036242). Written informed consent was obtained from all participants.

Author ORCID. (1D) Alison Tovar, 0000-0002-1559-592X.

\section{References}

1. Birch LL (2016) Learning to eat: behavioral and psychological aspects. Nestle Nutr Inst Workshop Ser 85, 125-134.

2. Section on Breastfeeding (2012) Breastfeeding and the use of human milk. Pediatrics 129, e827-e841. 
3. World Health Organization (2001) The World Health Organization's infant feeding recommendation. https://www. who.int/nutrition/topics/infantfeeding_recommendation/en/ (accessed March 2019).

4. Siega-Riz AM, Deming DM, Reidy KC et al. (2010) Food consumption patterns of infants and toddlers: where are we now? J Am Diet Assoc 110, 12 Suppl., S38-S51.

5. Heyman MB, Abrams SA; Section on Gastroenterology, Hepatology, and Nutrition; Committee on Nutrition (2017) Fruit juice in infants, children, and adolescents: current recommendations. Pediatrics 139, e20170967.

6. Malik VS, Pan A, Willett WC et al. (2013) Sugar-sweetened beverages and weight gain in children and adults: a systematic review and meta-analysis. Am J Clin Nutr 98, 1084-1102.

7. Pan L, Li R, Park S et al. (2014) A longitudinal analysis of sugar-sweetened beverage intake in infancy and obesity at 6 years. Pediatrics 134, Suppl. 1, S29-S35.

8. Park S, Li R \& Birch L (2015) Mothers' child-feeding practices are associated with children's sugar-sweetened beverage intake. J Nutr 145, 806-812.

9. Park S, Blanck HM, Sherry B et al. (2013) Regular-soda intake independent of weight status is associated with asthma among US high school students. J Acad Nutr Diet 113, 106-111.

10. Armfield JM, Spencer AJ, Roberts-Thomson KF et al. (2013) Water fluoridation and the association of sugar-sweetened beverage consumption and dental caries in Australian children. Am J Public Health 103, 494-500.

11. Park S, Sherry B, Foti K et al. (2012) Self-reported academic grades and other correlates of sugar-sweetened soda intake among US adolescents. J Acad Nutr Diet 112, 125-131.

12. Rehm CD, Penalvo JL, Afshin A et al. (2016) Dietary intake among US adults, 1999-2012. JAMA 315, 2542-2553.

13. Hamner HC, Perrine CG, Gupta PM et al. (2017) Food consumption patterns among US children from birth to 23 months of age, 2009-2014. Nutrients $\mathbf{9}$, E942.

14. Institute of Medicine (2015) Obesity in the Early Childhood Years: State of the Science and Implementation of Promising Solutions: Workshop Summary. Washington, DC: National Academies Press.

15. Taveras EM, Gillman MW, Kleinman KP et al. (2013) Reducing racial/ethnic disparities in childhood obesity: the role of early life risk factors. JAMA Pediatr 167, 731-738.

16. Larson N, Ward D, Neelon B et al. (2011) Preventing Obesity Among Preschool Children: How Can Child-Care Settings Promote Healthy Eating and Physical Activity? Princeton, NJ: Robert Wood Johnson Foundation.

17. Mennella JA, Ziegler P, Briefel R et al. (2006) Feeding Infants and Toddlers Study: the types of foods fed to Hispanic infants and toddlers. J Am Diet Assoc 106, Suppl. 1, S96-S106.

18. Miles G \& Siega-Riz AM (2017) Trends in food and beverage consumption among infants and toddlers: 2005-2012. Pediatrics 139, e20163290.

19. Demmer E, Cifelli CJ, Houchins JA et al. (2018) Ethnic disparities of beverage consumption in infants and children $0-5$ years of age; National Health and Nutrition Examination Survey 2011 to 2014. Nutr J 17, 78.

20. Hendricks K, Briefel R, Novak T et al. (2006) Maternal and child characteristics associated with infant and toddler feeding practices. J Am Diet Assoc 106, Suppl. 1, S135-S148.

21. Benjamin Neelon SE, Ostbye T, Bennett GG et al. (2017) Cohort profile for the Nurture Observational Study examining associations of multiple caregivers on infant growth in the Southeastern USA. BMJ Open 7, e013939.
22. Fein SB, Labiner-Wolfe J, Shealy KR et al. (2008) Infant Feeding Practices Study II: study methods. Pediatrics 122, Suppl. 2, S28-S35.

23. Briefel RR, Kalb LM, Condon E et al. (2010) The Feeding Infants and Toddlers Study 2008: study design and methods. J Am Diet Assoc 110, 12 Suppl., S16-S26.

24. Fein SB, Grummer-Strawn LM \& Raju TN (2008) Infant feeding and care practices in the United States: results from the Infant Feeding Practices Study II. Pediatrics 122, Suppl. 2, S25-S27.

25. Kleinman RE \& Greer FR (editors) (2013) Pediatric Nutrition, 7th ed. Elk Grove Village, IL: American Academy of Pediatrics.

26. Grummer-Strawn LM, Scanlon KS \& Fein SB (2008) Infant feeding and feeding transitions during the first year of life. Pediatrics 122, Suppl. 2, S36-S42.

27. Grimes CA, Szymlek-Gay EA \& Nicklas TA (2017) Beverage consumption among US children aged 0-24 months: National Health and Nutrition Examination Survey (NHANES). Nutrients 9, E264.

28. Reedy J \& Krebs-Smith SM (2010) Dietary sources of energy, solid fats, and added sugars among children and adolescents in the United States. J Am Diet Assoc 110, 1477-1484.

29. Bleich SN \& Vercammen KA (2018) The negative impact of sugar-sweetened beverages on children's health: an update of the literature. BMC Obes $\mathbf{5}, 6$.

30. Ha DH, Do LG, Spencer AJ et al. (2017) Factors influencing early feeding of foods and drinks containing free sugars - a birth cohort study. Int J Environ Res Public Health 14, E1270.

31. Fein SB, Labiner-Wolfe J, Scanlon KS et al. (2008) Selected complementary feeding practices and their association with maternal education. Pediatrics 122, Suppl. 2, S91-S97.

32. Tasevska N, DeLia D, Lorts C et al. (2017) Determinants of sugar-sweetened beverage consumption among low-income children: are there differences by race/ethnicity, age, and sex? J Acad Nutr Diet 117, 1900-1920.

33. Robinson S, Marriott L, Poole J et al. (2007) Dietary patterns in infancy: the importance of maternal and family influences on feeding practice. Br J Nutr $\mathbf{9 8}, 1029-1037$.

34. Bell LK, Golley RK, Daniels L et al. (2013) Dietary patterns of Australian children aged 14 and 24 months, and associations with socio-demographic factors and adiposity. Eur J Clin Nutr 67, 638-645.

35. Betoko A, Charles MA, Hankard R et al. (2013) Infant feeding patterns over the first year of life: influence of family characteristics. Eur J Clin Nutr 67, 631-637.

36. Heinig MJ, Follett JR, Ishii KD et al. (2006) Barriers to compliance with infant-feeding recommendations among lowincome women. J Hum Lact 22, 27-38.

37. Pawellek I, Grote V, Theurich M et al. (2017) Factors associated with sugar intake and sugar sources in European children from 1 to 8 years of age. Eur J Clin Nutr 71, 25-32.

38. Lande B, Andersen LF, Veierod MB et al. (2004) Breastfeeding at 12 months of age and dietary habits among breast-fed and non-breast-fed infants. Public Health Nutr 7, 495-503.

39. Perrine CG, Galuska DA, Thompson FE et al. (2014) Breastfeeding duration is associated with child diet at 6 years. Pediatrics 134, Suppl. 1, S50-S55.

40. Beauchamp GK \& Mennella JA (2009) Early flavor learning and its impact on later feeding behavior. $J$ Pediatr Gastroenterol Nutr 48, Suppl. 1, S25-S30. 